\title{
Setting Mechanisms of an Acidic Premixed Calcium Phosphate Cement
}

Jonas Åberg, Johanna Engstrand Unosson* and Håkan Engqvist

Applied Materials Science, Department of Engineering Sciences, Uppsala University, Sweden

\begin{abstract}
Premixed calcium phosphate cements ( $\mathrm{PCPC}$ ), where glycerol is used instead of water as mixing liquid, present better handling characteristics than water-based cements. However, the setting mechanisms of pCPC have not been described thoroughly. The aim of this paper is to increase the understanding of the setting mechanism of pCPC. The investigated cement starts to set when glycerol is exchanged with water via diffusion of glycerol out to the surrounding body fluid and water into the material. To better understand the water-glycerol exchange a method was developed where the setting depth of the cement was measured over time. Thermo gravimetric analysis (TGA) was used to determine the liquid exchange rate during setting. To study the influence of temperature on the crystalline end product, PCPC and water-mixed calcium phosphate cement (WCPC) were set at different temperatures and analyzed with X-ray diffraction (XRD). The setting depth measurements showed that the set layer of the PCPC grew with a speed proportional to $t^{0.51}$ at $37^{\circ} \mathrm{C}$. TGA results furthermore showed that less than $10 \%$ of the glycerol remained after 16 hours. Setting of $\mathrm{pCPC}$ at different temperatures showed that mainly brushite was formed at $5^{\circ} \mathrm{C}$, a mixture of brushite and monetite at $21^{\circ} \mathrm{C}$ and mainly monetite at $37^{\circ} \mathrm{C}$. It furthermore showed that brushite was the main phase after setting of wCPC, but some monetite was present in these cements. The study presents a new method for evaluation of $\mathrm{pCPC}$ that increases the understanding of their setting mechanism. Furthermore, the XRD results indicate that storage at $5^{\circ} \mathrm{C}$ could improve the shelf life of acidic PCPC
\end{abstract}

Keywords: Premixed; Calcium phosphate; Cements; Setting; Monetite; Brushite

\section{Introduction}

Calcium phosphate cements (CPCs) has gained widespread clinical use as bone void fillers since their introduction in the early 1980's [1-3]. Their chemical resemblance to bone allows the CPCs to integrate well with bone tissue. It furthermore allows a controlled resorption coupled to a fast bone in growth, the speed of which highly depends on both cement composition and porosity [4,5]. The setting mechanism is basically the same for all CPCs; one or more calcium phosphate salts are mixed with water, then the calcium salts dissolve and the water becomes supersaturated with respect to calcium and phosphate ions, which results in the precipitation of crystallites [6]. The precipitated crystallites grow and aggregate, causing the cement to set; resulting in hardened cement consisting of nano- to micrometer sized aggregated crystallites. The majority of the commercially used cements are delivered with separated powder and liquid phases, or as two separate liquids containing dissolved calcium phosphate salts $[7,8]$. However, these products require mixing in the operating room; giving rise to limited working times, expensive mixing equipment, higher risk of infection, and risk of improper mixing. In an attempt to solve this problem, premixed calcium phosphate cements (pCPC) have been proposed [9]. For this type of cements the mixing step is moved from the operating room to the production stage where the control can be more rigorous. The powder phase is here mixed with a non-aqueous liquid, e.g- glycerol or poly ethylene glycol $[9,10]$ instead of water. The setting of pCPC will therefore not theoretically start until the cement paste comes in contact with water. In an in vivo application this means that the setting reaction is started when the non-aqueous liquid diffuse out from the cement and is replaced with water from the body fluids, i.e, after cement injection or implantation. PCPCs have been evaluated in vivo showing good biocompatibility $[11,12]$. This type of premixed calcium phosphate pastes has been made from both basic [13] and acidic [14] calcium phosphate mixtures. When mixed with water, the basic CPCs normally precipitate into hydroxyapatite, while acidic CPCs normally form brushite as the set phase $[15,16]$. However, when the acidic CPCs have been prepared as premixed pastes the resulting phase after setting has been shown to be mainly monetite $[14,17,18]$. It is argued that the method of premixing the cements will cause a higher acidity locally in the cement, which could explain the formation of monetite instead of brushite [19]; however, this has not to the authors' knowledge been studied explicitly. Although the pCPCs have unlimited working times there are still issues preventing the pCPC from replacing wCPCs on the market; shelf life and setting time being key aspects that needs improvement before commercialization. One problem related to shelf life of the acidic pCPC is the premature reaction of the two starting powders (i.e., beta-tricalcium phosphate $(\beta-\mathrm{TCP})$, and monocalcium phosphate monohydrate (MCPM) reacts to form dicalcium phosphate anhydrous (DCPA or monetite)) due to presence of small amounts of water in the starting materials [20]. To prolong this unwanted reaction it is important to investigate the difference in phase composition during setting of the acidic PCPC in high (i.e., body $37^{\circ} \mathrm{C}$ ), respective low temperatures (i.e., room storage $21^{\circ} \mathrm{C}$, and fridge storage $5^{\circ} \mathrm{C}$ ).

In the literature available today the same methods are used for evaluating pCPCs and wCPCs. Although it is similar there are also large differences; mainly related to the setting behavior. In pCPC the in vivo exchange between glycerol and body fluids (water) plays a major part of the setting rate and will ultimately control the setting time and mechanism of $\mathrm{pCPC}$. This means that the $\mathrm{pCPC}$ setting start from the outside, where a set shell first is formed, and is moving inwards as

*Corresponding author: Johanna Engstrand Unosson, Applied Materials Science, Department of Engineering Sciences, Uppsala University, Sweden, Tel: +46(0)184717945; Fax: +46(0)184713572; E-mail: johanna.engstrand@angstrom.uu.se

Received August 29, 2013; Accepted November 08, 2013; Published November 16,2013

Citation: Jonas A, Johanna E, Hakan E (2013) Setting Mechanisms of an Acidic Premixed Calcium Phosphate Cement. Bioceram Dev Appl 3: 070. doi: 10.4172/2090-5025.1000070

Copyright: @ 2013 Jonas A, et al. This is an open-access article distributed under the terms of the Creative Commons Attribution License, which permits unrestricted use, distribution, and reproduction in any medium, provided the original author and source are credited. 
water penetrates into the bulk of the pCPC. This compared to wCPC where the setting starts simultaneously throughout the entire cement volume. This major difference between pCPCs and wCPCs causes a problem when measuring setting time according to ASTM standards with the Gillmore [21] or Vicat [22] needle methods. Both methods measures the time it takes for the cement to resist a specific load, which for pCPCs is more related to achieving a thick enough surface layer to resist this specific load, rather than the entire bulk material achieving a specified strength.

To improve the properties of pCPC, their setting mechanisms need to be better understood; furthermore, methods of evaluating pCPCs more explicitly need to be developed. The aim of this work is to evaluate the setting mechanisms of an acidic PCPC and present simple methods that can be used for further evaluation of pCPCs.

\section{Methods}

\section{Cement preparation}

pCPC was prepared by mixing the two calcium phosphate powders; $\beta$-tricalcium phosphate ( $\beta$-TCP, Sigma Aldrich, Germany) and monocalcium phosphate monohydrate (MCPM, Scharlau, Spain) with glycerol (anhydrous, $\mathrm{Mw}=92 \mathrm{~g} / \mathrm{mol}, \rho=1.26 \mathrm{~g} / \mathrm{cm} 3$, Sigma Aldrich, Germany) twice for 50 seconds using a vacuum mixer (Twister, Renfert, Germany). Paste stuck to walls and paddle was added to the rest of the paste between mixing steps. The calcium phosphate powders used had particle sizes of, $\beta$-TCP, 90\% $<50 \mu \mathrm{m}$, and MCPM, $90 \%<200 \mu \mathrm{m}$. The $\beta$-TCP powder contained $90 \mathrm{wt} \% \beta$-TCP and $10 \mathrm{wt} \%$ beta-calcium pyrophosphate $(\beta-\mathrm{CPP})$, and the MCPM starting material contained 93 wt $\%$ MCPM and 7 wt $\%$ monetite, established by XRD and Rietveld refinement. The starting powder composition and powder to liquid ratio $(\mathrm{P} / \mathrm{L})$ of the evaluated $\mathrm{pCPC}$ was chosen since this $\mathrm{pCPC}$ show a high injectability (close to $100 \%$ ) and good mechanical properties (12.3 $\pm 0.9 \mathrm{MPa}$ ) and is thus relevant for clinical use.

\section{Glycerol content}

Thermogravimetric analysis (TGA) was used to analyze the amount of remaining glycerol after immersion in phosphate buffered saline (PBS) solution. pCPC paste was prepared as previously described; $\beta$-TCP and MCPM were mixed in a 1:1 molar ratio and glycerol was added to achieve a $\mathrm{P} / \mathrm{L}$ of $3.5 \mathrm{~g} / \mathrm{ml}$. The samples were prepared by injecting the paste through a $3 \mathrm{ml}$ disposable syringe with a barrel diameter of $8.55 \mathrm{~mm}$ and an outlet diameter of $1.90 \mathrm{~mm}$ into cylindrical molds; (Ø $6 \mathrm{~mm}$ and height $3 \mathrm{~mm}$ ) open at one end. The moulded samples were subsequently immersed in $20 \mathrm{ml}$ of PBS ( $0.01 \mathrm{M}$ phosphate buffer, $0.0027 \mathrm{M}$ potassium chloride and $0.137 \mathrm{M}$ sodium chloride, $\mathrm{pH} 7.4$ ) at $37^{\circ} \mathrm{C}$ and stored in a sealed container for $30 \mathrm{~min}, 1,2,4,7$ and 16 hours, and 1 week. To obtain adequate sample size for the TGA the samples were divided into two equal pieces from which one was analyzed with the TGA. The measurements were performed on a TGAQ500 (TA Instruments, USA) with a heating ramp of $5^{\circ} \mathrm{C} / \mathrm{min}$ up to a maximum of $350^{\circ} \mathrm{C}$. A sample containing pure glycerol was analyzed as a control, showing that glycerol started to evaporate at $110^{\circ} \mathrm{C}$ and that all glycerol had evaporated at $230^{\circ} \mathrm{C}$. The amount of glycerol remaining in the samples after immersion in PBS was calculated from the weight loss between 110 and $230^{\circ} \mathrm{C}$ [23]. Three samples were prepared for each time point. The Korsmeyer-Peppas model of diffusion [24], normally used to describe drug release, was used to describe the diffusion of glycerol from the samples. Note that Korsmeyer-Peppas model is valid up to a release of $60 \%$ and the long term results were thus not fitted to the model.

\section{Setting depth}

The setting depth of the cement was investigated to evaluate the time it takes for water to penetrate into the bulk of a sample. Cement paste was prepared as previously described with a $\beta$-TCP and MCPM molar ratio of $1: 1$ and a glycerol content adding up to a $\mathrm{P} / \mathrm{L}$ of $3.5 \mathrm{~g} / \mathrm{ml}$. The pCPC was injected into cylindrical Teflon ${ }^{\circ}$ split molds, $(\varnothing 6 \mathrm{~mm}$ and height $12 \mathrm{~mm}$ ) open at one and immersed in $100 \mathrm{ml}$ of PBS at $37^{\circ} \mathrm{C}$. To eliminate water penetration from the sides the Teflon ${ }^{\circ}$ molds were placed in a silicone rubber casing leaving only the top of the sample exposed to the PBS. The setting depth was measured after $30 \mathrm{~min}, 1,2$, 4, 7 and 16 hours. When opening the split molds there was a clear limit between hard cement close to the exposed mold opening and unreacted cement paste. The setting depth was measured by gently removing the unreacted paste by hand and measuring the thickness of the hardened cement cylinder using a micrometer caliper (Mitutoyo, Japan), $n=6$ for all time points.

\section{Final phase composition}

In order to investigate the effect of temperature on the final phase composition, pCPC with $\mathrm{P} / \mathrm{L}$ of $3.5 \mathrm{~g} / \mathrm{ml}$ was allowed to set at three different temperatures. For comparison wCPCs were also prepared and investigated similar to the $\mathrm{pCPC}$. The wCPC contained the same starting powders as the $\mathrm{pCPC}$ but the glycerol was exchanged for distilled water and the $\mathrm{P} / \mathrm{L}$ was lowered to $2.5 \mathrm{~g} / \mathrm{ml}$ in order to obtain a workable paste. Since previous studies have shown that an excess of MCPM in wCPCs lead to the formation of monetite due to low $\mathrm{pH}$ [25], three different MCPM to $\beta$-TCP molar ratios were investigated for wCPC (i.e., 1:1, 7:3 and 3:7), while the PCPC only was investigated in a 1:1 molar ratio. Samples prepared in 7:3 and $3: 7$ ratios were only set at $37^{\circ} \mathrm{C}$, while the 1:1 molar ratio was tested at $5^{\circ} \mathrm{C}$ (only pCPC), $21^{\circ} \mathrm{C}$ and $37^{\circ} \mathrm{C}$. The samples were stored in $\mathrm{PBS}$ at the desired temperatures for 24 hours before phase analysis was performed. Since setting of $\mathrm{wCPC}$ at $37^{\circ} \mathrm{C}$ occurs almost instantly, all components for theses mixtures were kept at $37^{\circ} \mathrm{C}$ before mixing. Samples were analyzed using $\mathrm{X}$-ray diffraction (XRD, D8 Advanced, Bruker, USA) in a theta-theta setup with $\mathrm{Cu}$ $\mathrm{Ka}$ irradiation and nickel filter. Diffraction angles (20) 5-60 degrees were analyzed in steps of 0.034 degrees with 0.75 second per step and a rotation speed of $80 \mathrm{rpm}$. The phase composition was analyzed with Rietveld refinement using BGMN software. The reported values are an average of four measurements with the repeatability $(2.77 \mathrm{x}$ standard deviation) according to ASTM E177-13 [26] Structures used for the refinement were; monetite from PDF \#04-009-3755 [27], brushite from PDF \#04-013-3344 [28], $\beta$-TCP from PDF \#04-008-8714 [29], $\beta$-CPP from PDF \#04-009-3876 [30] and MCPM from PDF \#04-011-3010 [31].

\section{Results}

\section{Glycerol content}

The amount of glycerol present in the pCPC paste before setting was $27( \pm 1.8)$ wt $\%$ of the total sample weight, according to the TGA measurements (with the theoretical value being $26.3 \mathrm{wt} \%$ ). The diffusion of glycerol to the surrounding PBS between the start of the experiment until seven hours has been fitted to the Korsmeyer Peppas model of diffusion showing a coefficient of 0.45 (Figure 1). A release by $83 \%$ of glycerol was seen during the first seven hours after submersion in PBS, after which the tablets contained only $4.6( \pm 0.7) \mathrm{wt} \%$ of glycerol. After 16 hours there were $2.1( \pm 0.6)$ wt $\%$ glycerol remaining in the samples and after 8 days still $1.3( \pm 0.1)$ wt $\%$ glycerol were left. 


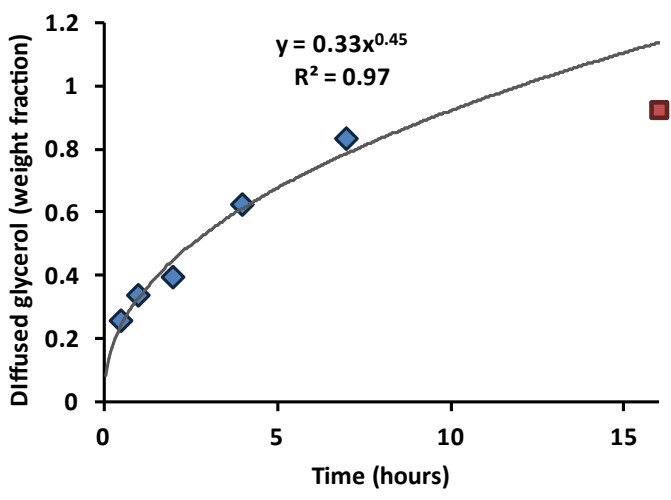

Figure 1: Weight fraction of glycerol diffused out from a premixed cement injected into $3 \mathrm{~mm}$ high moulds open at one end and placed in PBS for 0 to 16 hours. Results fitted against Korsmeyer Peppas model until 7 hours. Standard deviation for $n=3$ are around 0.02 for all points, and is too small to be visible in the figure.

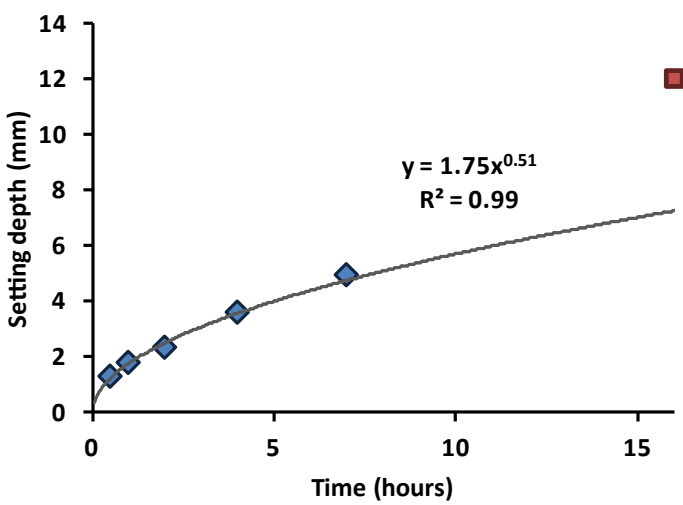

Figure 2: Setting depth of premixed cement from 30 min to 16 hours in $12 \mathrm{~mm}$ high moulds open at one end. Standard deviation for $n=6$ was less than 0.1 and is not visible in the figure. Trend line is fitted to the first five measure points.

\section{Setting depth}

The penetration of water into the pCPC causes the cement to set from the outside and in. The surface was set after roughly $30 \mathrm{~min}$. However, since the water needs to diffuse into the cement bulk before the cement fully sets, it took take several hours before the bulk volume had set. The setting depth was also fitted to Korsmeyer Peppas model and the exponent was found to be 0.51 (Figure 2). In the first 30 minutes the top $1.3( \pm 0.1) \mathrm{mm}$ of the cement had set and after 1 hour the set layer was $1.7( \pm 0.1) \mathrm{mm}$. After 16 hours all samples had set throughout the $12 \mathrm{~mm}$.

\section{Final phase composition}

The influence of setting temperature on the resulting phase of the CPCs can be seen in Figures 3 and 4. In all compositions approximately $4-5 \mathrm{wt} \%$ of $\beta$-CPP is seen, coming from the $\beta$-TCP used, which had $10 \mathrm{wt} \% \beta$-CPP present. The $\beta$-CPP is insoluble in water and is thus not participating in the setting reaction. Furthermore, some unreacted $\beta$-TCP was present, which indicated an incomplete setting reaction for all cements. When $\mathrm{pCPC}$ was set at low temperature $\left(5^{\circ} \mathrm{C}\right)$ mainly brushite was seen, with only small amounts of monetite $(4( \pm 1)$ wt $\%)$ present. At room temperature, both brushite (38 $( \pm 2)$ wt $\%)$ and monetite $(47( \pm 3) \mathrm{wt} \%)$ were present, and at $37^{\circ} \mathrm{C}$ mostly monetite and only small amounts of brushite $(9( \pm 2) \mathrm{wt} \%)$ were seen. The wCPC also showed a higher tendency to monetite formation at $37^{\circ} \mathrm{C}$ than at room temperature $\left(6( \pm 1) \mathrm{wt} \%\right.$ vs. $16( \pm 1) \mathrm{wt} \%$ for wCPC set at $21^{\circ} \mathrm{C}$ and $37^{\circ} \mathrm{C}$, respectively). However, brushite was the main phase for all wCPC, except the wCPC containing an excess of MCPM (7:3 ratio) where no brushite was present.

\section{Discussion}

The results from glycerol content and setting depth measurements show how the setting process of premixed cement clearly differs from the setting of water based cement. In the conventional wCPC the entire cement volume starts to set simultaneously, whereas in the case of the pCPC the setting of the cement depends on the diffusion of water into the cement. As seen in Figure 2, this is a process that takes several hours before the total cement volume has set. It is well known that reacts fast when mixed with water and additives (e.g- pyrophosphates [32,33], glycolic acid [34] and citric acid [34,35]) are thus needed in wCPC in order to delay the setting.

The diffusion of glycerol from the samples followed the Korsmeyer Peppas model with the coefficient being 0.45 , corresponds to a Fickian diffusion mechanism for cylindrical tablets [36]. Since Korsmeyer Peppas model only is valid up to a $60 \%$ release [36] it is not unexpected that the diffusion from the samples after seven hours ( $83 \%$ release) is no longer corresponding to the fitted curve (Figure 1). The decrease in release rate can be due to many factors, such as matrix changes during setting, resulting in smaller pores for the glycerol to penetrate, the lower concentration difference between the sample and the surrounding solution, and the fact that the PBS was not changed during the extent of the experiment.

Although the water-glycerol exchange between 7 hours and 16 hours was much slower than before 7 hours, the setting rate increased drastically after 7 hours (Figure 2). The authors have previously shown that only small amounts of water is needed to induce a setting reaction [17]. Furthermore, Gbureck et al. [20] showed that some setting actually can occur even without water due to the presence of non-evaporable water, this reaction is especially active at high temperatures. This means that not all glycerol has to be diffused out from the sample for the reaction to occur and explains the drastically faster setting towards the end of the experiment. To increase the initial growth rate of the set layer in PCPC, focus should be on increasing the water to mixing liquid exchange rate. This could be achieved by choosing a mixing liquid that is more miscible with water than glycerol, e.g- propylene glycol, which, with its lower viscosity and molecular size, could possibly allow faster water penetration. Another method could be to increase the particle size of the powder components, by this the mean distance between the individual powder particles would increase, which would facilitate water penetration.

As previously explained, the most widely used methods for measuring setting times of CPCs (Gillmore [21] or Vicat [22] needle) only measures the setting on the surface of the cement. When measuring the setting time of a pCPC the cement will be considered to have set when a layer of cement thick enough to carry the weight of the needle has been formed. pCPC with similar compositions show setting times (Gillmore needle method) around 30-60 minutes [18,19]; however, at this point most of the cement is still unreacted. Therefore, the authors consider that the method presented for evaluating the setting depth of 


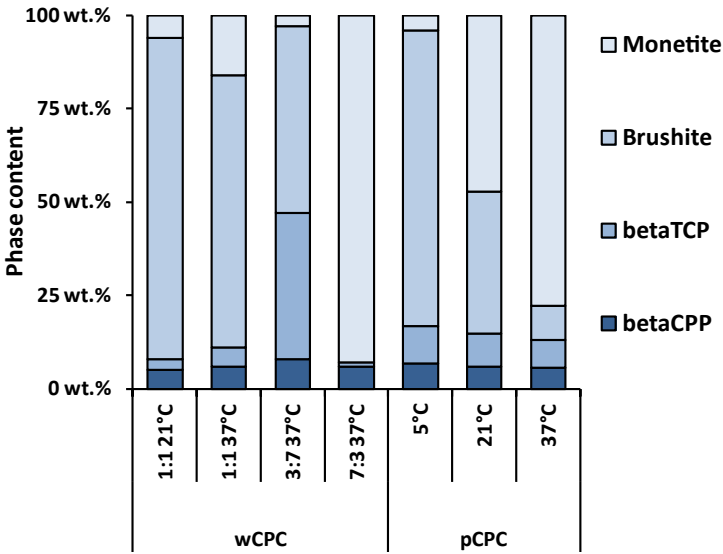

Figure 3: Phase composition of $\mathrm{PCPC}$ and $\mathrm{WCPC}$ after setting; the result presented is an average of four measurements. The relative error was between $1-3 \mathrm{wt} \%$ for all groups.

(a)

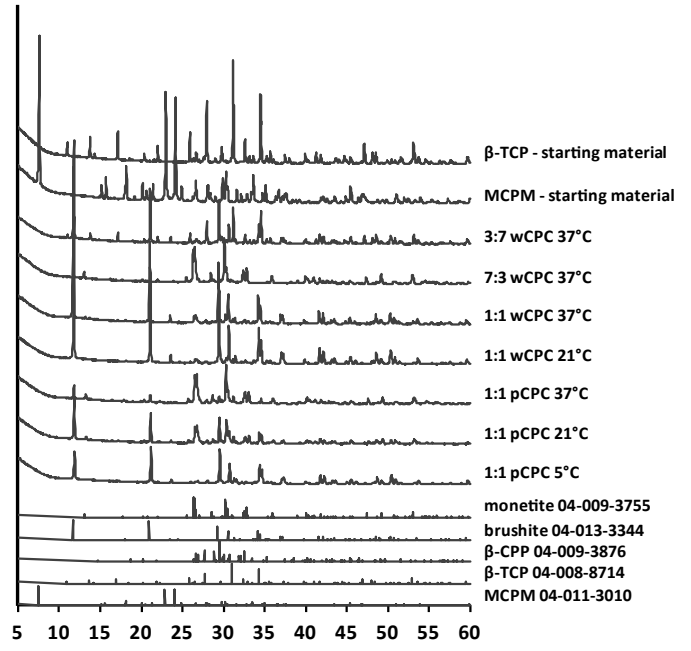

(b)

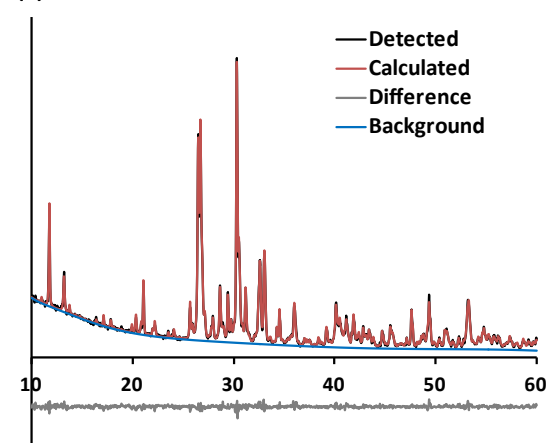

Figure 4: (a) Representative XRD plots for all compositions (one of four measurements is shown per composition). (b) Example of the Rietveld refinement accuracy as calculated by BGMN software on one of the PCPC samples set at $37^{\circ} \mathrm{C}$

the premixed cements is an important complement to the setting time measurements when evaluating premixed cements. The method is also interesting if the cements are combined with drugs such as BMP2 or antibiotics since it could allow for a better knowledge and control over the drug release.

As seen in the results from the XRD analysis the brushite/monetite ratio in an acidic CPC depends on several factors. It is know that wCPC with an excess of MCPM will produce monetite to a larger extent [25], which was also seen within this study (Figures 3 and 4). However, this was previously shown not be the explanation to the monetite formation in premixed cements since monetite is the predominant phase in $\mathrm{PCPC}$ formulations even with an excess of $\beta$-TCP [19]. Previous publications on acidic pCPC have reported that the cements form monetite at $37^{\circ} \mathrm{C}$ $[14,19]$ in accordance with the results in the present study. Although, monetite is the more stable phase in water, the activation energy for nucleation of brushite is lower than for monetite, and brushite is thus initially formed in all cements [37]. The formation of monetite $\left(\mathrm{CaHPO}_{4}\right)$ instead of brushite $\left(\mathrm{CaHPO}_{4} 2 \mathrm{H}_{2} \mathrm{O}\right)$ has previously been explained by the lack of water in the premixed cement causing a two step reaction where brushite is first formed and then dehydrated into monetite [20], see Eq. (1).

$$
\begin{aligned}
& \beta-\mathrm{Ca}_{3}\left(\mathrm{PO}_{4}\right)_{2}+\mathrm{Ca}\left(\mathrm{H}_{2} \mathrm{PO}_{4}\right) 2-\mathrm{H}_{2} \mathrm{O}+7 \mathrm{H}_{2} \mathrm{O} \\
& \rightarrow 4 \mathrm{CaHPO}_{4}-2 \mathrm{H}_{2} \mathrm{O} \rightarrow 4 \mathrm{CaHPO}_{4}+8 \mathrm{H}_{2} \mathrm{O}
\end{aligned}
$$

This reaction was suggested by Gbureck et al. [20], where a dry mixture of MCPM and $\beta$-TCP transformed into monetite during long time storage. The results presented in the present study indicate that the combination of lack of water and temperature is important in determining which phase is formed. If the low water content alone would cause the monetite formation, there would have been monetite present also in the pCPC set at $5^{\circ} \mathrm{C}$; however, only small amounts of monetite was seen at this temperature, which likely comes from the starting MCPM powder containing $7 \mathrm{wt} \%$ monetite. This indicates that the dehydration of brushite to monetite is energy consuming, and that some heat is needed for the dehydration to occur. In a study made by Grover et. al. [38] where a $\beta$-TCP/phosphoric cement was investigated, a similar temperature dependence for the formation of brushite or monetite was reported; at $37^{\circ} \mathrm{C}$ the main phase after reaction was brushite and at $55^{\circ} \mathrm{C}$ the main phase was monetite. Furthermore, studies have reported dehydration of brushite, forming monetite, at $37^{\circ} \mathrm{C}$ in PBS $[15,39,40]$. In the present study it was shown that brushite, in fact, can be formed also in the premixed system, but only at lower temperatures than in the water mixed system. In pCPC, brushite and monetite were present in almost equal amounts at room temperature, and at $5^{\circ} \mathrm{C}$ mostly brushite was present (Figures 3 and 4). These results are important for the storage of acidic pCPC, since they predict that a long shelf life could be obtained if no water is present in the formulation and the cement is kept at low temperatures. According to the results in this study a prefilled syringe with pCPC stored at $5^{\circ} \mathrm{C}$ would form brushite in the presence of water. Any water present in the syringe (e.g- non evaporable water and moist present during $\mathrm{pCPC}$ preparation) would be trapped in the brushite molecule $\left(\mathrm{CaHPO}_{4}\right.$ $2 \mathrm{H}_{2} \mathrm{O}$ ) since no decomposition to monetite and release of water (eq.1) is seen at these low temperatures. By using the anhydrous form of MCPM (monocalcium phosphate anhydrous, MCPA) instead of MCPM, in the formulation, the amount of water would be minimized, potentially further increasing the shelf life. However, a long-term shelf life study needs to be performed in order to confirm this.

Recently the interest in monetite based products has grown after in vivo studies have shown promising results $[12,41,42]$. The results from the present study in combination with previous literature show that cements that are considered to form brushite can also transform 
Citation: Jonas A, Johanna E, Hakan E (2013) Setting Mechanisms of an Acidic Premixed Calcium Phosphate Cement. Bioceram Dev Appl 3: 070. doi: $10.4172 / 2090-5025.1000070$

into monetite at $37^{\circ} \mathrm{C}$. Such cements have been researched extensively both in animal studies and clinically [43-45]. This indicates that the literature on brushite could be used to predict the in vivo behavior of monetite.

\section{Conclusions}

A new method for the evaluation of premixed cements improving the understanding of premixed cement setting has been developed. Deeper insights into the relationship between the brushite and monetite reaction mechanisms and chemistry have been attained through the determination of phase compositions after setting of both premixed and water-based formulations. The results show that premixed acidic cements could obtain a longer shelf life if stored at low temperatures and that acidic cements could form monetite in vivo when delivered in a premixed format. The setting depth measurements and glycerol diffusion studies clearly show that setting of premixed cements is initially controlled via the diffusion of water from the surrounding environment into the cement. However, other factors, e.g- elevated temperature, are increasing the setting rate towards the end.

\section{Acknowledgement}

The authors are grateful for financial support from FP7 NMP project Biodesign and the Swedish Research Council (GA 621-2011-6258)

\section{References}

1. Larsson S, Bauer TW (2002) Use of injectable calcium phosphate cement for fracture fixation: A review. Clinical Orthopaedics and Related Research 395 23-32.

2. Legeros R, Chohayeb A, Shulman A (1982) Apatitic calcium phosphates: possible dental restorative materials. J Dent Res 61: 343

3. Brown WE,Chow LC (1983) A New Calcium-Phosphate Setting Cement. J Dent Res 62: 672-672.

4. Apelt D, Theiss F, El-Warrak A O, Zlinszky K, Bettschart-Wolfisberger R, et al. (2004) In vivo behavior of three different injectable hydraulic calcium phosphate cements. Biomaterials 25: 1439-1451.

5. del Valle S, Mino N, Munoz F, Gonzalez A, Planell J A, et al. (2007) In vivo evaluation of an injectable Macroporous Calcium Phosphate Cement. J Mater Sci Mater Med 18: 353-361.

6. Fernandez E, Gil F J, Ginebra MP, Driessens FC, Planell JA, et al. (1999) Calcium phosphate bone cements for clinical applications. Part I: solution chemistry. J Mater Sci Mater Med 10: 169-176.

7. Torres J, Cuisinier F (2007) Use of a calcium phosphate bone cement in sinus floor augmentation, in combination with a cortico-cancellous graft. Presentation of the technique and illustration with a clinical case. Implantologie 87-94

8. Bohner M (2010) Design of ceramic-based cements and putties for bone graft substitution. Eur Cell Mater 20: 1-12.

9. Sugawara A, Chow LC, Takagi S,Chohayeb H (1990) In vitro Evaluation of the Sealing Ability of a Calcium-Phosphate Cement When Used as a Root-Canal Sealer-Filler. J Endodont 16: 162-165.

10. Xu HH, Carey LE, Simon CG,Takagi S,Chow LC (2007) Premixed calcium phosphate cements: synthesis, physical properties, and cell cytotoxicity. Dent Mater 23: 433-441.

11. Sugawara A, Fujikawa K, Hirayama S, Takagi S,Chow LC (2010) In Vivo Characteristics of Premixed Calcium Phosphate Cements When Implanted in Subcutaneous Tissues and Periodontal Bone Defects. Journal of Research of the National Institute of Standards and Technology 115: 277-290.

12. Aberg J, Henriksson HB, Engqvist H, Palmquist A, Brantsing C, et al. (2012) Biocompatibility and resorption of a radiopaque premixed calcium phosphate cement. Journal of Biomedical Materials Research Part A 100A: 1269-1278.

13. Carey LE, Xu HHK, Simon CG, Takagi S and Chow LC (2005) Premixed rapidsetting calcium phosphate composites for bone repair. Biomaterials 26: 5002-5014

14. Han B, Ma PW, Zhang LL, Yin YJ, Yao KD, et al. (2009) Beta-TCP/MCPMbased premixed calcium phosphate cements. Acta Biomater 5: 3165-3177.
15. Mirtchi AA, Lemaitre J,Terao N (1989) Calcium phosphate cements: study of the beta-tricalcium phosphate--monocalcium phosphate system. Biomaterials 10: $475-480$.

16. Engstrand J, Persson C, Engqvist H (2014) The effect of composition on mechanical properties of brushite cements. J Mech Behav Biomed Mater 29. $81-90$

17. Engstrand J, Aberg J, Engqvist $H$ (2013) Influence of water content on hardening and handling of a premixed calcium phosphate cement. Mater Sci Eng C 33: 527-531.

18. Åberg J, Engstrand J, Engqvist H (2013) Influence of particle size on hardening and handling of a premixed calcium phosphate cement. Journal of Materials Science: Materials in Medicine 24: 829-835.

19. Aberg J, Brisby H, Henriksson H B, Lindahl A, Thomsen P, et al. (2010) Premixed acidic calcium phosphate cement: Characterization of strength and microstructure. J Biomed Mater Res B Appl Biomater 93B: 436-441.

20. Gbureck U, Dembski S, Thull R, Barralet J E (2005) Factors influencing calcium phosphate cement shelf-life. Biomaterials 26: 3691-3697.

21. 1999 Standard Test Method for Time of Setting of Hydraulic-Cement Paste by Gillmore Needles. In: ASTM C266-99: ASTM International)

22. STM 2008 Standard Test Methods for Time of Setting of Hydraulic Cement by Vicat Needle. (Annual Book of ASTM Standards.

23. Dou B, Dupont V, Williams PT, Chen H, Ding Y (2009) Thermogravimetric kinetics of crude glycerol. Bioresour Technol 100: 2613-2620.

24. Korsmeyer R W and Peppas N A (1981).

25. Bohner M, Van Landuyt P, Merkle HP, Lemaitre J (1997) Composition effects on the $\mathrm{pH}$ of a hydraulic calcium phosphate cement. Journal of Materials Science: Materials in Medicine 8: 675-681.

26. ASTM Standard Practice for Use of the Terms Precision and Bias in ASTM Test Methods. In: E177-13.

27. Dickens B, Brown WE,Bowen JS (1972) A Refinement of Crystal-Structure of CaHPO4 (Synthetic Monetite). Acta Crystallogr B Struct Crystallogr Cryst Chem B 28: 797-806.

28. Curry NA, Jones DW (1971) Crystal Structure of Brushite, Calcium Hydrogen Orthophosphate Dihydrate - Neutron-Diffraction Investigation. J Chem Soc A 3725-3729.

29. Dickens B, Schroeder LW,Brown WE (1974) Crystallographic studies of the role of $\mathrm{Mg}$ as a stabilizing impurity in $\beta-\mathrm{Ca} 3(\mathrm{PO} 4) 2$. The crystal structure of pure $\beta$-Ca3(PO4)2. J Solid State Chem 10: 232-248.

30. Boudin S, Grandin A, Borel MM, Leclaire A, Raveau B (1993) Redetermination of the Beta-Ca2P2O7 Structure. Acta Crystallogr C Cryst Struct Commun 49: 2062-2064.

31. Schroeder LW, Prince E, Dickens B (1975) Hydrogen-Bonding in $\mathrm{Ca}(\mathrm{H} 2 \mathrm{PO} 4) 2$ $\mathrm{H}_{2} \mathrm{O}$ as Determined by Neutron-Diffraction. Acta Crystallogr B 31: 9-12.

32. Bohner M, Lemaitre J,Ring TA (1996) Effects of sulfate, pyrophosphate, and citrate ions on the physicochemical properties of cements made of betatricalcium phosphate-phosphoric acid-water mixtures. J Am Ceram Soc 79 : $1427-1434$.

33. Marshall RW,NancollaGh (1969) Kinetics of Crystal Growth of Dicalcium Phosphate Dihydrate. J Phys Chem 73: 3838-3844.

34. Mariño FT Torres J, Hamdan M, Rodríguez CR, Cabarcos EL (2007) Advantages of using glycolic acid as a retardant in a brushite forming cement. J Biomed Mater Res: Part B 83B: 571-579.

35. Giocondi JL, El-Dasher BS, Nancollas GH, Orme CA (2010) Molecula mechanisms of crystallization impacting calcium phosphate cements. Philos Trans A Math Phys Eng Sci 368: 1937-1961.

36. Dash S, Murthy PN, Nath L,Chowdhury P (2010) Kinetic modeling on drug release from controlled drug delivery systems. Acta poloniae pharmaceutica 67: 217-223.

37. Elliott JC (2002) Calcium phosphate biominerals. Rev Mineral Geochem 48 $427-453$.

38. Grover LM, Gbureck U, Young AM, Wright AJ, Barralet JE (2005) Temperature dependent setting kinetics and mechanical properties of beta-TCP- 
Citation: Jonas A, Johanna E, Hakan E (2013) Setting Mechanisms of an Acidic Premixed Calcium Phosphate Cement. Bioceram Dev Appl 3: 070. doi: $10.4172 / 2090-5025.1000070$

pyrophosphoric acid bone cement. Journal of Materials Chemistry 15: 49554962.

39. Bohner M, Lemaitre J, VanLanduyt P, Zambelli PY, Merkle HP, et al. (1997) Gentamicin-loaded hydraulic calcium phosphate bone cement as antibiotic delivery system. J Pharm Sci 86: 565-572.

40. Cama G, Barberis F, Capurro M, Di Silvio L, Deb S (2011) Tailoring brushite for in situ setting bone cements. Materials Chemistry and Physics 130: 1139-1145.

41. Tamimi F, Torres J, Bassett D, Barralet J, Cabarcos EL (2010) Resorption of monetite granules in alveolar bone defects in human patients. Biomaterials 31 : 2762-2769.

42. Tamimi F, Torres J, Gbureck U, Lopez-Cabarcos E, Bassett DC, et al.
(2009) Craniofacial vertical bone augmentation: A comparison between 3D printed monolithic monetite blocks and autologous onlay grafts in the rabbit. Biomaterials 30: 6318-6326.

43. Joeris A, Ondrus S, Planka L, Gal P, Slongo T (2010) ChronOS Inject in Children with Benign Bone Lesions - Does It Increase the Healing Rate? European Journal of Pediatric Surgery 20: 24-28.

44. Lacout JL, Mejdoubi E, Hamad M (1996) Crystallization mechanisms of calcium phosphate cement for biological uses. Journal of Materials Science-Materials in Medicine 7: 371-374.

45. Ryf C, Goldhahn S, Radziejowski M, Blauth M, Hanson B (2009) A New Injectable Brushite Cement: First Results in Distal Radius and Proximal Tibia Fractures. European Journal of Trauma and Emergency Surgery 35: 389-396. 